America, kiss my ass! I didn't mean that, laughing myself sideways down the culde-sac and into the Franz Kafka Re-election Committee headquarters: Prague comes to Prairie Village, a rather cuddly ghost, still miraculously unweary of understanding the speakable sadness of a dried-up port.

\title{
EAVESDROPPER WITHOUT A PORT, BECOMING SMALL
}

Arabs are twisting downshore, members of a leading desert tribe. Perhaps that have lost contact with their highschool peers, lovers, golfers and fishermen.

Waves can be as formless: over illuminations, cocktail nuts drift. The Captain in his bathtub tells terrible stories, false stories of breathless beginnings in a shivery cove, which turn out to be the same as this one by a thick thread of broken paddles.

The fabulous highwayman considers remaining on an island never adequately explained, without regard to time, space or spectators. And by rubbing granite cliffs together morning becomes Thor Heyerdahl on his way to work, and a cannon announces Spring groping its way as a hearse among lotus blossoms.

The zebras want to visit Chicago: it is said they have memories but they don't. They receive their energies from a completely unknown source, some malignant force is directing them. The electricity from our nightmares?

Full of illusory weathervanes and silent cocks that sleep past noon, in a field of marble? 